\title{
Cerebrospinal fluid drainage options for posthemorrhagic hydrocephalus in premature neonates
}

\author{
Opções de drenagem liquórica em neonatos prematuros com hidrocefalia pós hemorrágica \\ José Roberto Tude Melo', Rosane Klein Passos², Marcelo Liberato Coelho Mendes de Carvalho'
}

\begin{abstract}
Objective: The literature describes various cerebrospinal fluid (CSF) drainage techniques to alleviate posthemorrhagic hydrocephalus in preterm newborns; however, consensus has not been reached. The scope of this study was describing a case series of premature neonates with posthemorrhagic hydrocephalus and assessing the outcomes of different approaches used for CSF diversion. Methods: A consecutive review of the medical records of neonates with posthemorrhagic hydrocephalus treated with CSF drainage was conducted. Results: Forty premature neonates were included. Serial lumbar puncture, ventriculosubgaleal shunt, and ventriculoperitoneal shunt were the treatments of choice in $25 \%, 37.5 \%$ and $37.5 \%$ of the cases, respectively. Conclusion: Cerebrospinal fluid diversion should be tailored to each case with preference given to temporary CSF drainage in neonates with lower age and lower birth-weight, while the permanent ventriculoperitoneal shunt should be considered in healthier, higher birth-weight neonates born closer to term.
\end{abstract}

Keywords: cerebral hemorrhage; hydrocephalus; cerebrospinal fluid.

\section{RESUMO}

Objetivo: A literatura descreve várias opções de drenagem liquórica (DL) para alivio da hidrocefalia pós-hemorrágica (HPH) em neonatos prematuros; contudo, não existe um consenso sobre a melhor abordagem. 0 escopo deste estudo foi descrever uma série de casos de neonatos prematuros, portadores de HPH, verificando os resultados de diferentes técnicas utilizadas para DL. Métodos: Revisão consecutiva dos prontuários de neonatos com diagnostico de HPH submetidos a DL. Resultados: Quarenta recém-nascidos prematuros foram incluídos. A punção lombar seriada (PL), a derivação ventriculosubgaleal (VSG) e a derivação ventrículo peritoneal (VP) foram o tratamento escolhido em 25\%, 37,5\% e 37,5\% dos casos, respectivamente. Conclusão: As opções de DL devem ser avaliadas caso a caso, sendo dada preferência às drenagens temporária em prematuros com idade e peso mais baixos ao nascer, enquanto o shunt definitivo (derivação VP) pode ser considerado naqueles prematuros mais saudáveis, com idade e peso superiores.

Palavras-chave: hemorragia cerebral; hidrocefalia; líquido cefalorraquidiano.

Intraventricular hemorrhage (IVH) has been a major cause of mortality among premature neonates for more than 40 years $^{1,2}$ and is associated with neonatal encephalopathy, subsequent subtle apnea, and death ${ }^{1,2,3,4}$. Low birth-weight premature neonates are more vulnerable to IVH and, depending on the IVH grade, to posthemorrhagic hydrocephalus (PHH). Posthemorrhagic hydrocephalus can evolve to progressive $\mathrm{PHH}$, and in more severe cases, to periventricular hemorrhagic infarct, hemorrhagic cerebral injury, and periventricular leukomalacia ${ }^{1,4.5}$. Between $15 \%$ to $20 \%$ of neonates born with a weight less than 1,500 g are estimated to develop IVH. Further, $75 \%$ of those with Papile grade III or IV hemorrhages develop progressive PHH and need a permanent shunt ${ }^{4,6}$.
The literature does not clearly indicate any standardized protocols for the best PHH treatment options in this patient group. Rather, a variety of approaches, ranging from serial lumbar punctures (LP), transcutaneous transfontanellar puncture, external ventricular drainage, and ventriculosubgaleal shunt (with or without subcutaneous reservoir) to the endoscopic third ventriculostomy are used ${ }^{4,6,7,8,9,10,11,12,13}$. Ventriculoperitoneal (VP) shunts are contraindicated as a first option in low birth-weight $(<1.500 \mathrm{~g})$ premature neonates due to the higher risk of complications associated with the implanted prosthesis and are reserved for selected cases ${ }^{4,9,11,13}$. The scope of this study was describing a case series of premature neonates with $\mathrm{PHH}$ and assessing the outcomes of different approaches used for CSF diversion.

${ }^{1}$ Hospital Pediátrico Martagão Gesteira, Unidade de Neurocirurgia Pediátrica, Salvador BA, Brasil;

${ }^{2}$ Hospital Pediátrico Martagão Gesteira, Unidade de Radiologia, Salvador BA, Brasil.

Correspondence: José Roberto Tude Melo; Rua Jose Duarte, 114 / 2ªndar; 40050-050 Salvador BA, Brasil; Email: robertotude@martagaogesteira.org.br

Conflict of interest: There is no conflict of interest to declare.

Received 20 January 2016; Received in final form 05 January 2017; Accepted 14 March 2017. 


\section{METHODS}

\section{Study design and inclusion criteria}

This single-center study was approved by the Brazilian Research Ethics Committee (registration number 38819114.7.0000.5557). This retrospective review and observational study included all premature neonates admitted with a diagnosis of $\mathrm{PHH}$ to the neonatal intensive care unit at a Reference Public Pediatric Hospital in Salvador da Bahia, Brazil between December 2009 and December 2014. The diagnosis of PHH identified by a transcranial ultrasonography, and treated with a CSF drainage procedure, and a minimum follow-up of three months for the assessment of treatment outcomes.

\section{Definitions of prematurity, IVH and $\mathrm{PHH}$}

Premature neonates were defined as those born before 37 weeks of gestation and as low birth weight when weight-at-birth was less than $1.500 \mathrm{~g}^{4}$. In all patients, transcranial ultrasonography was performed by a senior radiologist with more than ten years of experience using a classical transfontanellar approach with a $1.9-6-\mathrm{MHz}$ curvilinear transducer (Toshiba Aplio 100 with color Doppler).

The Papile system was used for grading IVH by transcranial ultrasonography. Briefly, grade I was defined as hemorrhage restricted to the ventricular subependymal matrix occupying a maximum of $10 \%$ of the ventricles. Grade II and III were defined as hemorrhage comprising $10-50 \%$ and more than $50 \%$ of the ventricular system, respectively. If the hemorrhage extended to the periventricular, i.e., parenchymal, regions, it was considered as a grade IV IVH ${ }^{14}$.

A diagnosis of PHH secondary to $\mathrm{IVH}$ was made when the anterior horns width of the lateral ventricles was $\geq 6 \mathrm{~mm}$ as measured in the anterior coronal plane at the level of the septum pellucidum (median line), with the midpoint in the lateral wall of the lateral ventricle (at the level of caudate nucleus and the foramen of Monro) (Figure) $)^{4,15,16}$. Comorbidities considered as severe were global hypotonia associated to bradycardia, cardiorespiratory arrest, respiratory failure, cutaneous cyanosis, sepsis and other infections associated with clinical and laboratory worsening.

\section{Surgical intervention}

Conditions that were included that required a neurosurgical evaluation were bulging fontanelles, an increase in the cranial circumference, bradycardia, and other signs of intracranial hypertension, associated with transcranial ultrasonography showing ventriculomegaly (anterior horns width showing progressive increase) and IVH grades III and IV.

The CSF drainage is commonly indicated in cases of progressive increases in cranial circumference ( $\geq 2$ standard deviations above the patient's age group during the first week), bulging fontanelles, or changes in respiratory patterns, associated with progressive widening of the ventricular system detected by transcranial ultrasonography ${ }^{13,17,18}$. In cases of ventriculomegaly from ex vacuo hydrocephalus (i.e. without bulging fontanelles, increase in the

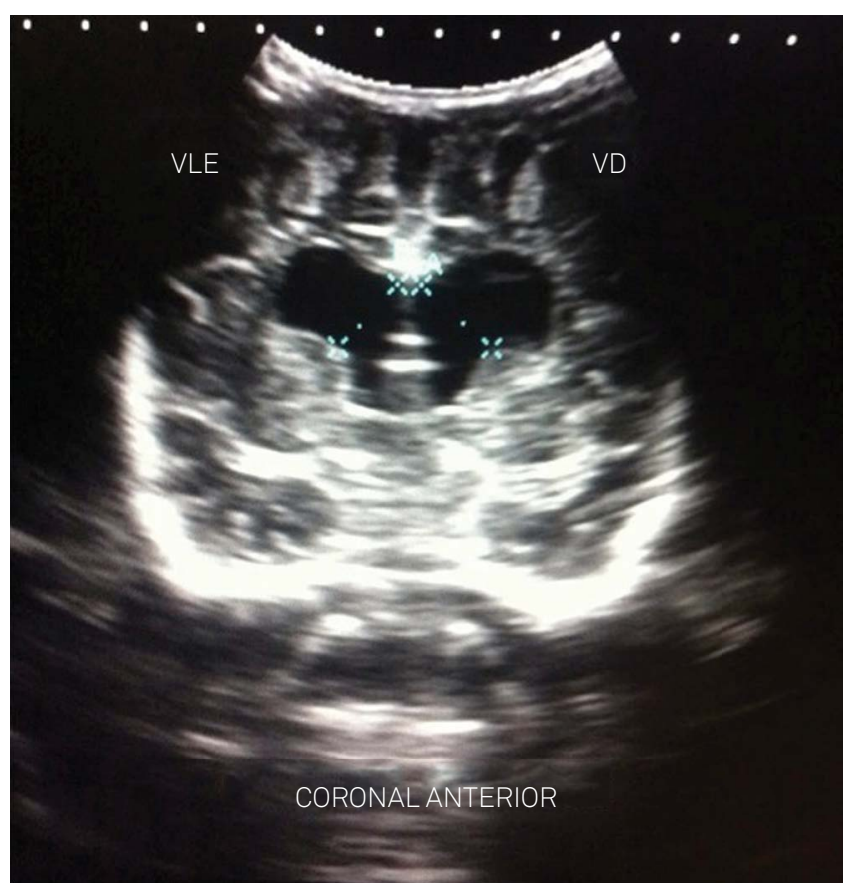

Figure. Transcranial ultrasonography: the width of the anterior horns of the lateral ventricles was measured in the anterior coronal plane at the level of the septum pellucidum (median line), with the midpoint in the lateral wall of the lateral ventricle (at the level of caudate nucleus and the foramen of Monro).

cranial circumference, bradycardia, or other signs of intracranial hypertension), a nonsurgical treatment was proposed.

The study did not assess the preferred CSF drainage method among transcutaneous transfontanellar puncture, external ventricular drainage, or ventriculostomy, as our pediatric neurosurgical team prefers not use them, in cases of neonates with

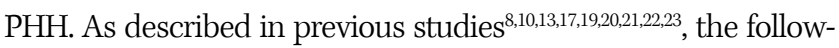
ing techniques were employed for CSF drainage to resolve PHH: Serial $L P$ was performed at the L3-L4 or L4-L5 level, with the anatomical landmark as an imaginary line traced from the iliac crest to the lumbar column. A valveless ventriculosubgaleal shunt with subcutaneous reservoirs was placed with an incision near the external angle of the anterior fontanelle, followed by the detachment of subgaleal space and the introduction of a 3-cm catheter into the anterior ventricular horn; the catheter was then connected to the reservoir and the scalp. The VP shunt was placed as follows: an incision was made near the lambdoid suture, and a mini-laparotomy was performed for tunneling of the distal catheter of the VP shunt. A burr-hole was made for the osseous and dural exposition, the dura was opened, and a $5-\mathrm{cm}$ catheter was introduced into the posterior ventricular horn. The proximal and distal catheters were connected and fixed in the periosteum, and the distal catheter was introduced into the peritoneal cavity under direct vision. Finally, the musculoaponeurotic, subcutaneous, and cutaneous layers were closed. In this study, the serial LPs and ventriculosubgaleal shunts were considered to be temporary CSF drainage options, while the VP shunt was considered as the only permanent CSF drainage approach. 


\section{Follow-up and complications}

Patients were evaluated for the persistence or enlargement of hydrocephalus, CSF leak, shunt infection, failure, or mechanical dysfunctions for at least three months after CSF diversion. Hydrocephalus was assessed by the enlargement of cranial circumference or bulging fontanelles during follow-up and transcranial ultrasonography showing anterior horns width $\geq 6 \mathrm{~mm}$ measured in the anterior coronal plane.

\section{Statistical analysis}

Epi Info ${ }^{\mathrm{TM}}$ version 7, a public domain statistical software for epidemiology developed by the US Centers for Disease Control and Prevention, was used for database analysis. Some results were presented as descriptive statistics. Measures of central tendency (mean, mode, and median) were calculated and presented where relevant. The chi-squared test was used to compare ratios with a confidence interval of $95 \%$. The differences were considered statistically significant if the $p$-value was $<0.05$.

\section{RESULTS}

Forty-nine preterm neonates with $\mathrm{PHH}$ were treated by CSF drainage during the study period; however, nine patients were excluded because they were lost to follow-up. Thus, 40 preterm neonates were included in the final analysis. The median gestational age and birth weight were 28 weeks (range; $24-35$ weeks) and 1,105 g (range; 600-2,800 g), respectively. Patient characteristics are shown in Table 1.

Table 1. General characteristics of preterm neonates treated for CSF diversion due to PHH (Salvador, Brazil, 2009-2014).

\begin{tabular}{|c|c|}
\hline General characteristics & $n=40$ \\
\hline Male sex, n (\%) & $22(55)$ \\
\hline Median gestational age in weeks & $28(24-35)$ \\
\hline Median weight at birth in g & $1,105(600-2,800)$ \\
\hline \multicolumn{2}{|l|}{ IVH grade, $n(\%)$} \\
\hline Papile grade III & $28(70)$ \\
\hline Papile grade IV & $12(30)$ \\
\hline Complications after birth*, n (\%) & $35(88)$ \\
\hline
\end{tabular}

Twenty-five patients $(62.5 \%)$ were treated with temporary CSF drainage approaches: 10 patients (25\%) with serial LP, and 15 cases (37.5\%) with a ventriculosubgaleal shunt as the first option to alleviate PHH. Ventriculoperitoneal shunts were used in 15 neonates (37.5\%) to treat PHH as the first option, generally with low-pressure valves.

The median age and weight of patients treated with temporary drainage methods were 27 weeks (range; 24-35 weeks) and $867 \mathrm{~g}$ (range; 600-1730g), respectively, while the median age and weight of patients treated with VP shunts were 32 weeks (range; 26-35 weeks) and $2000 \mathrm{~g}$ (range; 1500-2800g), respectively (Table 2). All of the patients treated with temporary CSF drainage methods were considered clinically more severely affected, had previous infections, or suffered from severe comorbidities. In contrast, significantly fewer patients treated with the VP shunt had severe comorbidities (66\%; $p=0.004$ ) (Table 2), and none in the latter group had comorbidities related to sepsis or other infections.

Regarding the initial method chosen for PHH treatment, $50 \%$ (5/10) of those undergoing serial LP and 46\% (7/15) of those undergoing ventriculosubgaleal shunt required VP shunts during the course of PHH evolution (12/25, 48\%) (Table 3). During the follow-up period of all enrolled patients, 68\% (27/40) were considered as permanent ventricular drainage dependents and were using VP shunts. The incidence of progressive PHH was higher in case of IVH grade III ( $79 \%$ vs $42 \%$; $p=0.02$ ).

Among the 27 patients considered as permanent ventricular drainage dependents, $44 \%$ (12/27) had infectious complications or mechanical dysfunction (obstruction or overdrainage). Ten of these patients had received a VP shunt as the first option for PHH treatment (Table 3). This group that received a VP shunt as the first option for PHH treatment $(\mathrm{n}=15)$ had a higher incidence of complications than those treated for progressive $\mathrm{PHH}$ with a VP shunt during the follow-up period ( $\mathrm{n}=12)(66 \%$ vs $16 \%, \mathrm{p}=0.01$ ). There was a total of five deaths $(5 / 40 ; 13 \%)$. The average and median time of follow-up was 11.8 months (DP +/- 16.2 months) and three months (range; 3-60 months).

\section{DISCUSSION}

Intraventricular hemorrhage is the leading cause of hydrocephalus in premature neonates, especially those

Table 2. Characteristics of preterm neonates according to the initial PHH treatment approaches (Salvador, Brazil, 2009-2014).

\begin{tabular}{|c|c|c|c|}
\hline \multirow{2}{*}{ Criteria } & \multirow{2}{*}{$\begin{array}{c}\text { Temporary CSF Diversions* } \\
n=25(\%)\end{array}$} & \multirow{2}{*}{$\begin{array}{c}\text { Permanent CSF Diversions ** } \\
n=15(\%)\end{array}$} & \multirow{2}{*}{$\mathrm{p}$} \\
\hline & & & \\
\hline \multicolumn{4}{|l|}{ Median } \\
\hline Age in weeks & $27(24-35)$ & $32(26-35)$ & - \\
\hline Weight in $g$ & $867(600-1730)$ & $2000(1500-2800)$ & \\
\hline Severe comorbidities***, n (\%) & $25(100)$ & $10(66)$ & 0.004 \\
\hline \multicolumn{4}{|l|}{ IVH Grade, n (\%) } \\
\hline Papile grade III & $14(56)$ & $14(93)$ & 0.01 \\
\hline Papile grade IV & $11(44)$ & $01(6)$ & \\
\hline
\end{tabular}


Table 3. CSF drainage approaches and complications in preterm neonates with PHH (Salvador, Brazil, 2009-2014).

\begin{tabular}{|c|c|c|c|}
\hline \multirow{2}{*}{ Variable } & \multicolumn{3}{|c|}{$\begin{array}{l}\text { First option for therapeutic relief of hydrocephalus } \\
\qquad n=40\end{array}$} \\
\hline & $\begin{array}{c}\text { LP } \\
(n=10)\end{array}$ & $\begin{array}{l}\text { VSG shunt } \\
(n=15)\end{array}$ & $\begin{array}{l}\text { VP shunt } \\
(n=15)\end{array}$ \\
\hline Retreatment due to persistence or enlargement of hydrocephalus*, n (\%) & $5(50)$ & $7(46)$ & - \\
\hline CSF leak, n (\%) & - & $4(26)$ & - \\
\hline Shunt malfunction or infection, $\mathrm{n}(\%)$ & - & - & $10(66)$ \\
\hline
\end{tabular}

with low birth-weight, and generally occurs within the first four days of life ${ }^{11}$. Low gestational age and low birth-weight increase the risk for developing $\mathrm{IVH}^{4,6,11,17}$, a finding consistent with the median age (28 weeks) and weight $(1,105 \mathrm{~g})$ of the patients enrolled in this study. There is a minor male predominance reported in previous studies ${ }^{17}$.

Most of the patients included in the current study were diagnosed with Papile grade III IVH. This finding is in agreement with previously reported risk of $\mathrm{PHH}$ in this patient population ${ }^{6,13,23}$. These patients are commonly referred to pediatric neurosurgery for either temporary or permanent CSF diversion to relieve PHH-induced intracranial hypertension ${ }^{6,13,17,22,23}$, while grade I and II patients are usually not referred for neurosurgical evaluation due to the lower incidence of PHH and intracranial hypertension. The high number of patients with clinical complications such as hypotonia, bradycardia, cardiac arrest, respiratory failure, skin cyanosis, sepsis, and other infections, highlight the susceptibility of these patients as well as the challenges in their management $t^{4,17}$, both of which are clinically considered in deciding the appropriate treatment options for CSF diversion in $\mathrm{PHH}$ cases $^{23}$.

The method chosen for CSF drainage in PHH cases does not follow a specific protocol, and varies with the neurosurgeon's experience, the age and weight of the premature neonate, the presence of associated comorbidities, the characteristics of the ventricular system assessed by imaging studies, and the clinical presentation. In this study, none of the patients received an initial treatment with transcutaneous transfontanellar puncture, external ventricular drainage, or ventriculostomy. Transcutaneous transfontanellar puncture is not used as a first choice at our hospital due to the associated risks, which include CSF leak, porencephalic cysts, and multiloculated hydrocephalus ${ }^{4}$. External ventricular drainage is not used for temporary relief of hydrocephalus as a first option in premature neonates due to the risks associated with infection and accidental removal of the external ventricular drainage, which have been observed in other reference centers as well $1^{4,6,10,13,17,19,22,23}$. While still considered as a controversial method in neonates with IVH, several groups have recommended the irrigation of ventricles for the removal of blood clots, the coagulation of choroid plexus, and the opening of the third ventricle floor by ventricular endoscopy, with the aim of reducing progressive $\mathrm{PHH}$ rates or, at a minimum, of delaying the use of permanent shunts in select cases ${ }^{20,21}$. At our hospital, we do not have experience in the use of ventriculostomy in premature neonates; rather, this technique is reserved for use in children over two years of age who are diagnosed with obstructive and noncommunicating hydrocephalus, or congenital cerebral cysts (arachnoid cysts).

In this study, we found a tendency to use temporary drainage methods in infants with lower gestational age and birth weight, while the VP shunt was reserved for older, heavier and healthier children, a finding that corroborates previously published data regarding CSF diversion options ${ }^{23}$. The serial LP was chosen in low birth-weight premature neonates with more severe and clinically unstable comorbidities, as it is the fastest method that does not require general anesthesia or transportation to the operating room; the procedure can be performed in the neonatal intensive care unit. In cases of more stable clinical conditions, the ventriculosubgaleal shunt as an alternative temporary drainage approach is considered, especially in infants with grade III IVH. As seen in Table 2, in addition to age and weight, additional factors including associated morbidities and the IVH grade, aid the neurosurgeon in deciding between a temporary and a permanent CSF drainage.

Ventriculoperitoneal shunt was chosen as the first option for relief in $37.5 \%$ of patients, similar to that found in previous studies $(34 \%)^{17}$. In several reference centers, the VP shunt is often chosen as a first-line treatment modality for IVH-associated PHH (range; 53-72\%) ${ }^{13,23}$. This divergence in published studies on the subject shows the lack of a standardized protocol across different institutions. Our findings corroborate earlier studies suggesting that the VP shunt should be chosen as the initial therapy in select cases, specifically in older preterm neonates who are heavier, healthier, and are without infections $\mathbf{s}^{4,172,23}$.

As previous studies ${ }^{6}$, among the temporary ventricular drainage options, we found that serial LP in up to $50 \%$ of the cases resolved PHH. The ventriculosubgaleal shunt achieved resolution in $54 \%$ of the cases, comparable to the serial LP. The advantages of the ventriculosubgaleal shunt over the serial LP include the likelihood and the ease of serial punctures in the reservoir if intracranial hypertension develops ${ }^{10,13,23}$. 
In this study, $48 \%$ of the patients were initially treated with temporary methods for $\mathrm{PHH}$ resolution and were subsequently treated by the VP shunt based on monitoring for the clinical signs of intracranial hypertension, such as bulging fontanelles and increased head circumference. The predictive factors that can aid in the replacement of a temporary ventricular drainage method with a permanent one are not yet established ${ }^{4,13,17}$. In general, depending on the study sample, the percentage of patients depending on a permanent shunt in the follow-up period ranges from $30 \%$ to $75 \%{ }^{4,6,15}$, in agreement with our findings that show $68 \%$ of our patients needing the permanent shunt.

Ventriculoperitoneal shunt complications in these patients are often higher than those observed in the general pediatric population. In certain series, more than $50 \%$ of VP shunt recipients need further VP shunt exchanges and revisions ${ }^{6,23}$. Our data corroborate these earlier findings; the patients treated with a VP shunt for initial PHH management had higher complication rates than those treated with a VP shunt as a second option during the follow-up period. In a series of children with congenital hydrocephalus described previously by our team ${ }^{24}$, we observed a much lower incidence of VP shunt-related complications than those observed in the current series, which confirms the need for extreme care in the selection of $\mathrm{PHH}$ patients for a VP shunt as a first CSF drainage option.

The overall mortality rates of IVH in preterm neonates may vary from $30 \%$ to $58 \%$, and are higher in those with Papile grade IV $\mathrm{IVH}^{4,6,25}$. The mortality rate in this study refers to only those patients undergoing neurosurgical evaluation. Moreover, nine patients were excluded from the final analysis due to the lack of the minimum stipulated follow-up period of three months. The mortality rate in our cohort (13\%) is similar to the previously-published studies that included only the IVH patients with $\mathrm{PHH}$ undergoing neurosurgical treatment ${ }^{23}$.

Only the CSF drainage methods used for PHH treatment at the hospital where the study was conducted were analyzed, and do not necessarily reflect the reality of other reference centers. Finally, we would also like to indicate that only those patients assessed by a pediatric neurosurgeon were included in this study, while those determined by the neonatologist not to qualify for neurosurgical evaluation were excluded.

In conclusion, temporary CSF diversion methods should be the first option for $\mathrm{PHH}$ treatment in premature neonates, especially in those small for gestational age and those with low birth-weight. A serial LP should be considered in more severe cases as general anesthesia, transportation, or excessive handling of the patients are not required. The ventriculosubgaleal shunt is another option, especially in those with more stable clinical conditions and controlled comorbidities. Only in the older, heavier, and healthier newborns, especially in those with Papile IVH grade III, should the VP shunt be considered as the first option for $\mathrm{PHH}$ treatment. As reflected in our findings, which showed complications in patients who were treated with the VP shunt as the first option, ventricular endoscopy should be considered and evaluated as an alternative option in $\mathrm{PHH}$ treatment to delay the implantation of a permanent shunt.

\section{References}

1. Bassan $\mathrm{H}$. Intracranial hemorrhage in the preterm infant: understanding it, preventing it. Clin Perinatol. 2009;36(4):737-62. https://doi.org/10.1016/j.clp.2009.07.014

2. Harcke HT, Naeye RL, Storch A, Blanc WA. Perinatal cerebral intraventricular hemorrhage. J Pediatr. 1972;80(1):37-42. https://doi.org/10.1016/S0022-3476(72)80450-5

3. Lozano R, Naghavi M, Foreman K, Lim S, Shibuya K, Aboyans V et al. Global and regional mortality from 235 causes of death for 20 age groups in 1990 and 2010: a systematic analysis for the Global Burden of Disease Study 2010. Lancet. 2012;380(9859):2095-128. https://doi.org/10.1016/S0140-6736(12)61728-0

4. Robinson S. Neonatal posthemorrhagic hydrocephalus from prematurity: pathophysiology and current treatment concepts.J Neurosurg Pediatr. 2012;9(3):242-58.https://doi.org/10.3171/2011.12.PEDS11136

5. Fadzli F, Ramli NM, Rahmat K, Ganesan D. Neonatal post-hemorrhagic hydrocephalus resulting in foraminal septae-radiological technique and surgical implications. Childs Nerv Syst. 2013;29(1):159-62. https://doi.org/10.1007/s00381-012-1923-5

6. Zanten SA, Haan TR, Ursum J, Sonderen L. Neurodevelopmental outcome of post-hemorrhagic ventricular dilatation at 12 and 24 months corrected age with high-threshold therapy. Eur J Paediatr Neurol. 2011;15(6):487-92. https://doi.org/10.1016/j.ejpn.2011.04.011

7. Bassan H, Eshel R, Golan I, Kohelet D, Ben Sira L, Mandel D et al. Timing of external ventricular drainage and neurodevelopmental outcome in preterm infants with posthemorrhagic hydrocephalus. Eur J Paediatr Neurol. 2012;16(6):662-70. https://doi.org/10.1016/j.ejpn.2012.04.002

8. Karas CS, Baig MN, Elton SW. Ventriculosubgaleal shunts at Columbus Children's Hospital: neurosurgical implant placement in the neonatal intensive care unit. J Neurosurg. 2007;107(3 Suppl):220-3. https://doi.org/10.3171/PED-07/09/220

9. Limbrick DD Jr, Mathur A, Johnston JM, Munro R, Sagar J, Inder T et al. Neurosurgical treatment of progressive posthemorrhagic ventricular dilation in preterm infants: a 10-year single-institution study. J Neurosurg Pediatr. 2010;6(3):224-30. https://doi.org/10.3171/2010.5.PEDS1010

10. Melo JR, Di Rocco F, Bourgeois M, Puget S, Blauwblomme T, Sainte-Rose C et al. Surgical options for treatment of traumatic subdural hematomas in children younger than 2 years of age. J Neurosurg Pediatr. 2014;13(4):456-61. https://doi.org/10.3171/2014.1.PEDS13393

11. Okazaki M, Fukuhara T, Namba Y. Delayed germinal matrix hemorrhage induced by ventriculoperitoneal shunt insertion for congenital hydrocephalus. J Neurosurg Pediatr. 2013;12(1):67-70. https://doi.org/10.3171/2013.4.PEDS12599

12. Perret GE, Graf CJ. Subgaleal shunt for temporary ventricle decompression and subdural drainage. J Neurosurg. 1977;47(4):590-5. https://doi.org/10.3171/jns.1977.47.4.0590 
13. Wellons JC 3rd, Shannon CN, Kulkarni AV, Simon TD, Riva-Cambrin J, Whitehead WE et al. A multicenter retrospective comparison of conversion from temporary to permanent cerebrospinal fluid diversion in very low birth weight infants with posthemorrhagic hydrocephalus. J Neurosurg Pediatr. 2009;4(1):50-5. https://doi.org/10.3171/2009.2.PEDS08400

14. Papile LA, Burstein J, Burstein R, Koffler H. Incidence and evolution of subependymal and intraventricular hemorrhage: a study of infants with birth weights less than 1,500 gm. J Pediatr. 1978;92(4):529-34. https://doi.org/10.1016/S0022-3476(78)80282-0

15. Brouwer A, Groenendaal F, Haastert IL, Rademaker K, Hanlo P, Vries L. Neurodevelopmental outcome of preterm infants with severe intraventricular hemorrhage and therapy for post-hemorrhagic ventricular dilatation. J Pediatr. 2008;152(5):648-54. https://doi.org/10.1016/j.jpeds.2007.10.005

16. Brouwer MJ, Vries LS, Groenendaal F, Koopman C, Pistorius LR, Mulder EJ et al. New reference values for the neonatal cerebral ventricles. Radiology. 2012;262(1):224-33. https://doi.org/10.1148/radiol.11110334

17. Riva-Cambrin J, Shannon CN, Holubkov R, Whitehead WE, Kulkarni AV, Drake J et al. Center effect and other factors influencing temporization and shunting of cerebrospinal fluid in preterm infants with intraventricular hemorrhage. J Neurosurg Pediatr. 2012;9(5):473-81. https://doi.org/10.3171/2012.1.PEDS11292

18. Melo JR, Pacheco P, Melo EN, Vasconcellos A, Passos RK. Clinical and ultrasonographic criteria for using ventriculoperitoneal shunts in newborns with myelomeningocele. Arq Neuropsiquiatr. 2015;73(9):759-63. https://doi.org/10.1590/0004-282X20150110

19. Alan N, Manjila S, Minich N, Bass N, Cohen AR, Walsh $\mathrm{M}$ et al. Reduced ventricular shunt rate in very preterm infants with severe intraventricular hemorrhage: an institutional experience. J Neurosurg Pediatr. 2012;10(5):357-64. https://doi.org/10.3171/2012.7.PEDS11504

20. Chamiraju P, Bhatia S, Sandberg DI, Ragheb J. Endoscopic third ventriculostomy and choroid plexus cauterization in posthemorrhagic hydrocephalus of prematurity. J Neurosurg Pediatr. 2014;13(4):433-9. https://doi.org/10.3171/2013.12.PEDS13219

21. Smyth MD, Tubbs RS, Wellons JC 3rd, Oakes WJ, Blount JP, Grabb PA. Endoscopic third ventriculostomy for hydrocephalus secondary to central nervous system infection or intraventricular hemorrhage in children. Pediatr Neurosurg. 2003;39(5):258-63. https://doi.org/10.1159/000072871

22. Tubbs RS, Smyth MD, Wellons JC 3rd, Blount JP, Grabb PA, Oakes WJ. Alternative uses for the subgaleal shunt in pediatric neurosurgery. Pediatr Neurosurg. 2003;39(1):22-4. https://doi.org/10.1159/000070875

23. Willis B, Javalkar V, Vannemreddy P, Caldito G, Matsuyama J, Guthikonda B et al. Ventricular reservoirs and ventriculoperitoneal shunts for premature infants with posthemorrhagic hydrocephalus: an institutional experience. J Neurosurg Pediatr. 2009;3(2):94-100. https://doi.org/10.3171/2008.11.PEDS0827

24. Melo JR, Melo EN, Vasconcellos AG, Pacheco P. Congenital hydrocephalus in the northeast of Brazil: epidemiological aspects, prenatal diagnosis, and treatment. Childs Nerv Syst. 2013;29(10):1899-903. https://doi.org/10.1007/s00381-013-2111-y

25. Clark CE, Clyman RI, Roth RS, Sniderman SH, Lane B, Ballard RA. Risk factor analysis of intraventricular hemorrhage in low-birth-weight infants. J Pediatr. 1981;99(4):625-8. https://doi.org/10.1016/S0022-3476(81)80276-4 